\title{
Article \\ Biomechanical Comparison of Fixation Stability among Various Pedicle Screw Geometries: Effects of Screw Outer/Inner Projection Shape and Thread Profile
}

\author{
Ming-Kai Hsieh ${ }^{1}\left(0\right.$, Yun-Da Li ${ }^{1,2}$, Mu-Yi Liu ${ }^{2}$, Chen-Xue Lin ${ }^{2}$, Tsung-Ting Tsai ${ }^{1} \oplus$, Po-Liang Lai ${ }^{1}(\mathbb{D}$ \\ and Ching-Lung Tai ${ }^{1,2, *(D)}$ \\ 1 Department of Orthopedic Surgery, Spine Section, Bone and Joint Research Center, Chang Gung Memorial \\ Hospital, Taoyuan 33302, Taiwan; mk660628@gmail.com (M.-K.H.); yunda1222@hotmail.com (Y.-D.L.); \\ tsai1129@gmail.com (T.-T.T.); polianglai@gmail.com (P.-L.L.) \\ 2 Graduate Institute of Biomedical Engineering, Chang Gung University, Taoyuan 33302, Taiwan; \\ zero_790723@hotmail.com (M.-Y.L.); asw156437@gmail.com (C.-X.L.) \\ * Correspondence: taicl@mail.cgu.edu.tw
}

Citation: Hsieh, M.-K.; Li, Y.-D.; Liu, M.-Y.; Lin, C.-X.; Tsai, T.-T.; Lai, P.-L.; Tai, C.-L. Biomechanical Comparison of Fixation Stability among Various Pedicle Screw Geometries: Effects of Screw Outer/Inner Projection Shape and Thread Profile. Appl. Sci. 2021, 11, 9901. https://doi.org/10.3390/ app11219901

Academic Editors: Cheng-Kung Cheng, Tsung-Yuan Tsai, Liao Wang and Songtao $\mathrm{Ai}$

Received: 30 August 2021

Accepted: 20 October 2021

Published: 22 October 2021

Publisher's Note: MDPI stays neutral with regard to jurisdictional claims in published maps and institutional affiliations.

Copyright: (c) 2021 by the authors. Licensee MDPI, Basel, Switzerland. This article is an open access article distributed under the terms and conditions of the Creative Commons Attribution (CC BY) license (https:/ / creativecommons.org/licenses/by/ $4.0 /)$.

\begin{abstract}
The proper screw geometry and pilot-hole size remain controversial in current biomechanical studies. Variable results arise from differences in specimen anatomy and density, uncontrolled screw properties and mixed screw brands, in addition to the use of different tapping methods. The purpose of this study was to evaluate the effect of bone density and pilot-hole size on the biomechanical performance of various pedicle screw geometries. Six screw designs, involving three different outer/inner projections of screws (cylindrical/conical, conical/conical and cylindrical/cylindrical), together with two different thread profiles (square and V), were examined. The insertional torque and pullout strength of each screw were measured following insertion of the screw into test blocks, with densities of 20 and $30 \mathrm{pcf}$, predrilled with $2.7-\mathrm{mm} / 3.2-\mathrm{mm} / 3.7-\mathrm{mm}$ pilot holes. The correlation between the bone volume embedded in the screw threads and the pullout strength was statistically analyzed. Our study demonstrates that V-shaped screw threads showed a higher pullout strength than S-shaped threads in materials of different densities and among different pilot-hole sizes. The configuration, consisting of an outer cylindrical shape, an inner conical shape and V-shaped screw threads, showed the highest insertional torque and pullout strength at a normal and higher-than-normal bone density. Even with increasing pilot-hole size, this configuration maintained superiority.
\end{abstract}

Keywords: pedicle screw; screw loosening; pilot hole; bone density

\section{Introduction}

Rigid intervertebral fixation is the first priority, in the currently used spinal-corrective surgery methods, in terms of achieving final fusion [1-3]. Fixation devices, including pedicle screws, hooks, wires, plates and interbody cages, have been commonly used in recent decades, and pedicle screws have gained increasingly widespread acceptance [4-8].

Failed back surgery syndrome resulting from pseudarthosis, ranging in incidence from 5 to $35 \%$, has been reported in recent years [9-13]. Improvements in bone graft, the local environment, instrumentation and surgical techniques have all contributed to better fusion rates [13]. In addition to biological factors, studies comparing surgical techniques for managing and preventing pseudarthrosis have improved with the use of rigid instrumented fixation [14].

The screw geometry, consisting of the thread shape, core shape and pitch depth, and insertional factors, such as the pilot-hole size, insertional depth and trajectory, contribute to the fixation stability of pedicle screws and have been discussed in recent years. However, the proper screw geometry and pilot-hole size remain controversial in current biomechanical studies [15-21]. Inconsistent results arise from the use of allogeneic or xenogeneic 
vertebrae with different anatomical characteristics and density distributions, various screw materials, mixed screw brands, and uncontrolled partial threads and tapping methods in pilot-hole size studies $[15,17,21-23]$. To the best of the authors' knowledge, the most effective screw geometry configuration has not yet been determined by nonbiased biomechanical testing [24,25]. In our study, we tested the pullout strength and insertional torque of six different screw geometry configurations, namely three outer/inner diameter shapes and two thread profiles that are commonly used in clinical spinal surgeries, in standard polyurethane foam test blocks.

The purpose of the study was to evaluate the effect of bone density and pilot-hole size on the biomechanical performance of various screw geometries, resolve the dilemma of screw loosening and investigate the recommended proper screw geometry for clinical applications.

\section{Materials and Methods}

\subsection{Pedicle Screw Geometries}

Six types of pedicle screws were fabricated using the same materials and processes based on three different outer/inner diameter shapes (cylindrical/conical, conical/conical and cylindrical/cylindrical) and two types of threads (square- or V-shaped). The length of the thread coverage was controlled at $33 \mathrm{~mm}$, and the screws were grouped as follows: cylindrical/cylindrical-square (Cy/Cy-S), cylindrical/conical-square (Cy/Co-S), conical/conical-square (Co/Co-S), cylindrical/cylindrical-V (Cy/Cy-V), cylindrical/conical$\mathrm{V}(\mathrm{Cy} / \mathrm{Co}-\mathrm{V})$ and conical/conical-V $(\mathrm{Co} / \mathrm{Co}-\mathrm{V})$. The outer/inner projection of the screws differed mainly in the taper of the major and minor diameter from the hub to the tip. The $\mathrm{Cy} / \mathrm{Cy}$ screws maintained a constant outer/inner diameter $(6.0 \mathrm{~mm} / 4.0 \mathrm{~mm})$ from hub to tip; the $\mathrm{Cy} / \mathrm{Co}$ screws maintained a constant outer diameter $(6.0 \mathrm{~mm})$ but had a core diameter that tapered by $40 \%$, from $4.0 \mathrm{~mm}$ at the hub to $2.4 \mathrm{~mm}$ at the tip; and both the outer and core diameters of the Co/Co screws tapered by $40 \%$ (from 6.0 to $3.6 \mathrm{~mm}$ and 4.0 to $2.4 \mathrm{~mm}$ for the outer and core diameters, respectively). For all screw types, the thread pitch was $2.4 \mathrm{~mm}$ (Figure 1). The different configurations of the outer/inner diameter $(\mathrm{Cy} / \mathrm{Cy}, \mathrm{Cy} / \mathrm{Co}, \mathrm{Co} / \mathrm{Co}$ ) led to different thread depths at various cross sections for specific single screws (e.g., the $\mathrm{Cy} / \mathrm{Co}$ screw had a larger thread depth at the screw tip than at the screw hub). The outer/inner diameter projection and actual photographs of various screws are shown in Figure 2.

\subsection{Test Blocks}

Commercially available synthetic bone with a density of $20 \mathrm{pcf}(0.32 \mathrm{~g} / \mathrm{cc}$; model \# 1522-03) and 30 pcf (0.64 g/cc; model \#1522-04, Pacific Research Laboratory Inc., Vashon Island, WA, USA), which simulated differences in bone density, was used as a substitute for cadaveric spinal bone because of its consistent and homogeneous structural properties. This eliminated the effects of the variability of bone properties and morphometry. The synthetic bone was composed of rigid polyurethane foam and had a rectangular shape (test block) with dimensions of $13 \mathrm{~cm} \times 18 \mathrm{~cm} \times 4 \mathrm{~cm}$. The foam type and representative bone density were regulated and standardized by an American Society of Testing Materials (ASTM) protocol, and the test blocks provided a consistent and uniform material for use as a standard material when performing mechanical tests that utilized orthopedic devices or instruments [26]. 

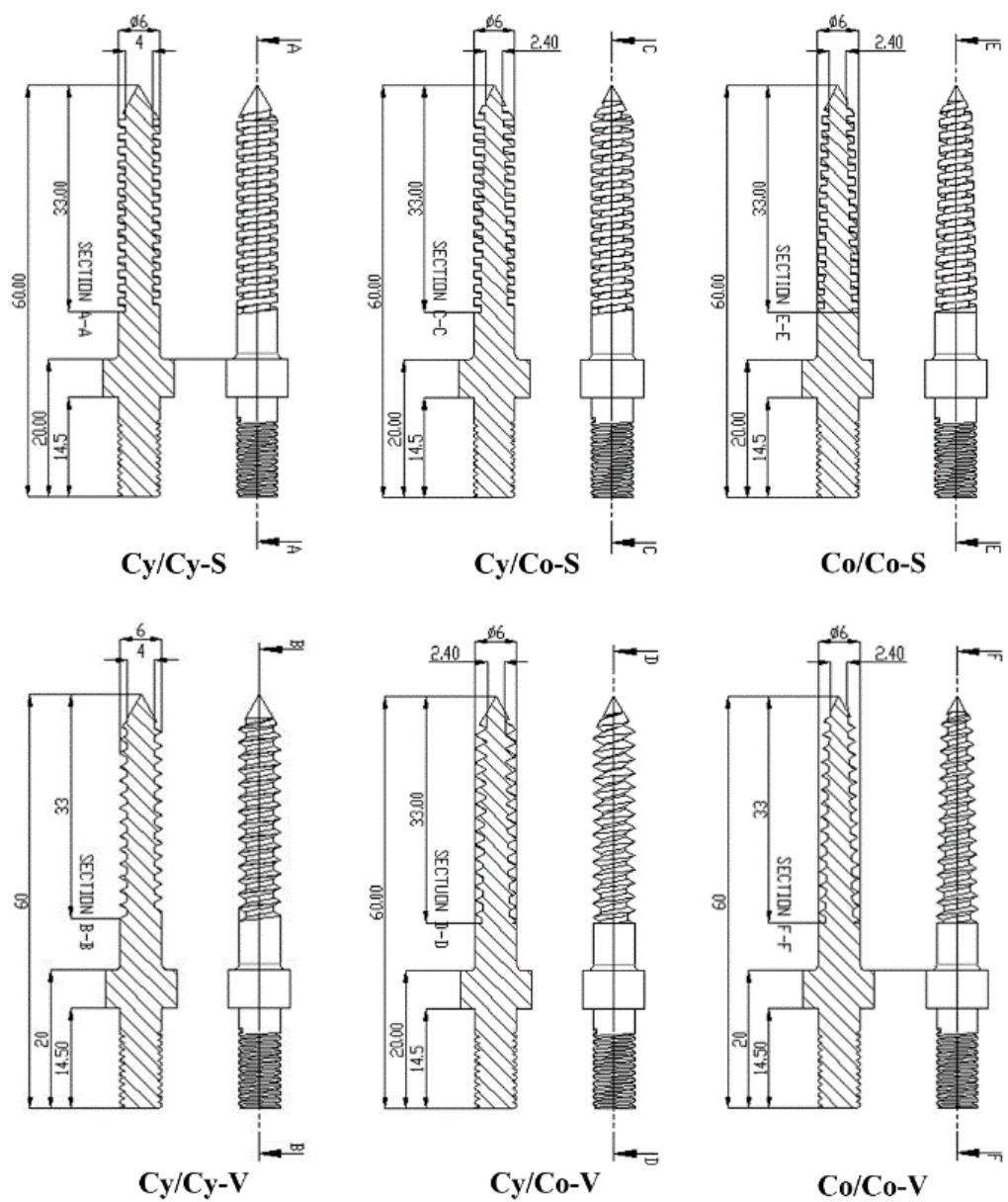

Figure 1. Schematic drawings showing six types of pedicle screws. The outer/inner projection of the screws differed mainly in the taper of the major and minor diameter from the hub to the tip. The $\mathrm{Cy} / \mathrm{Cy}$ screws maintained a constant outer/inner diameter $(6.0 \mathrm{~mm} / 4.0 \mathrm{~mm})$ from hub to tip; the Cy/Co screws maintained a constant outer diameter $(6.0 \mathrm{~mm})$ but had a core diameter that tapered by $40 \%$, from $4.0 \mathrm{~mm}$ at the hub to $2.4 \mathrm{~mm}$ at the tip; and both the outer and core diameters of the Co/Co screws tapered by $40 \%$ (from 6.0 to $3.6 \mathrm{~mm}$ and 4.0 to $2.4 \mathrm{~mm}$ for the outer and core diameters, respectively). For all screw types, the thread pitch was $2.4 \mathrm{~mm}$.

\subsection{Specimen Preparation}

\subsubsection{Comparison of Different Bone Mineral Densities}

To clarify the effect of bone mineral density on the biomechanical performance of six screw geometries, five blocks of each screw design were employed for each bone density of 20 and 30 pcf; a pilot-hole diameter of $3.7 \mathrm{~mm}$ and depth of $45 \mathrm{~mm}$ were set in this model. The same insertional depth and angle, and the integrity of the test blocks, were confirmed postinsertion by $\mathrm{X}$-ray imaging (Figure 3). 


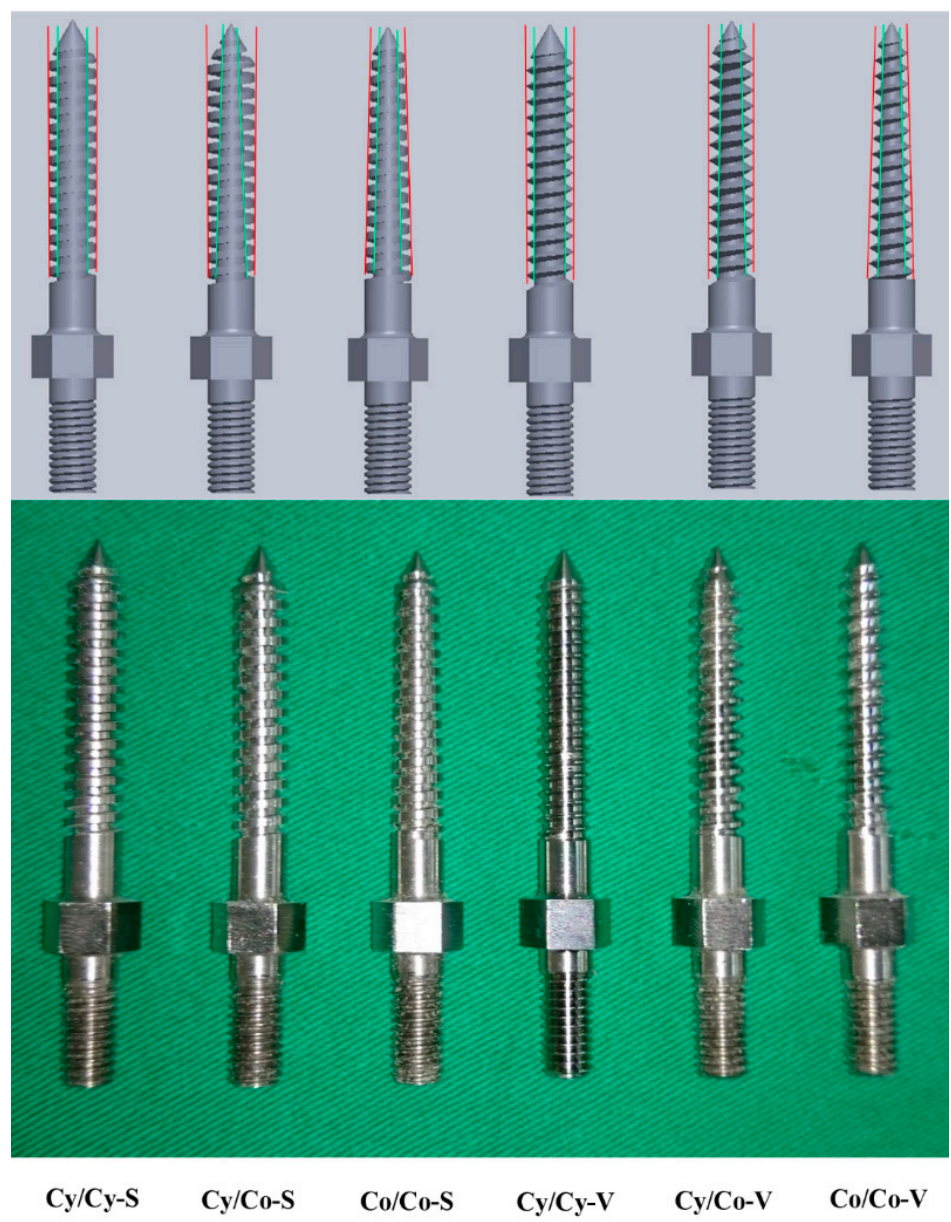

Figure 2. Schematic drawings (upper) and photographs (bottom) of six types of pedicle screws with different outer/inner projections ( $\mathrm{Cy} / \mathrm{Cy}, \mathrm{Cy} / \mathrm{Co}, \mathrm{Co} / \mathrm{Co}$ ) and thread profiles (square-shaped and V-shaped).

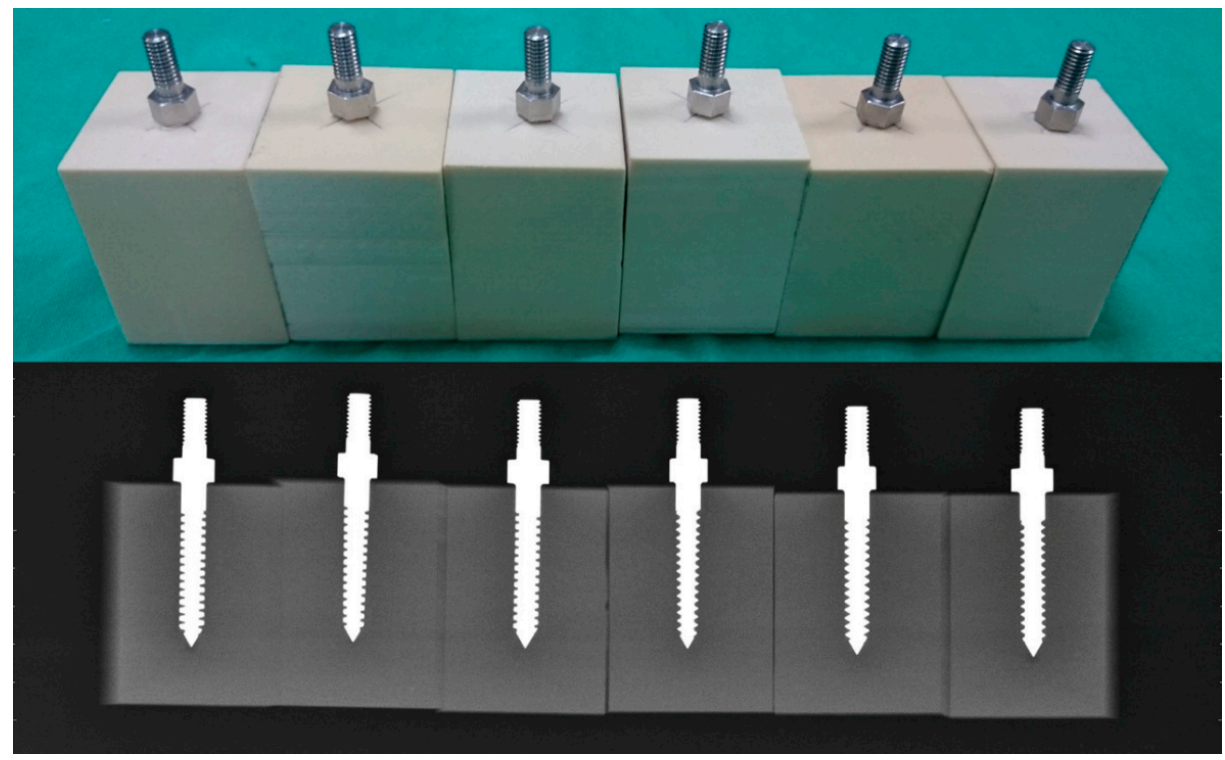

Figure 3. Photographs (upper) and radiological images (bottom) of the test blocks after the insertion of screws with various geometries. The inserted screws from left to right are Cy/Co-S, Co/Co-S, $\mathrm{Cy} / \mathrm{Cy}-\mathrm{S}, \mathrm{Co} / \mathrm{Co}-\mathrm{V}, \mathrm{Cy} / \mathrm{Co}-\mathrm{V}$ and $\mathrm{Cy} / \mathrm{Cy}-\mathrm{V}$, respectively. 


\subsubsection{Comparison of Different Pilot-Hole Sizes}

The pilot holes were drilled into the blocks (20 pcf in density) at a depth of $45 \mathrm{~mm}$ with three different diameters: $2.7,3.2$ and $3.7 \mathrm{~mm}$. To minimize the experimental variation caused by vibration of the hand-held drill, all pilot holes were prepared using a standard procedure. The test block was clamped on a vise, and a drilling machine (DP8; Rexon Industrial Corp., Taichung, Taiwan) was used to create a pilot hole. All screws were inserted to the same depth using a gauge of consistent depth, allowing room for attachment to testing equipment. X-ray imaging of all instrumented test blocks was performed to ensure the same insertional depth and angle.

\subsection{Biomechanical Testing}

During screw insertion, the maximal insertional torque was measured using a torquemeasuring hex driver (60DB3-S, Tohnich, Tokyo, Japan). A trajectory axis that was perpendicular to the insertional plane of the test block and a consistent insertional depth were confirmed using X-ray imaging prior to pullout testing. Following screw insertion, the specimen was placed on a specially designed universal fixture that was capable of self-alignment to ensure vertical screw pullout. The pedicle screw head was fixed into a 10-mm-diameter rod with an inner thread matching the outer thread of the screw head. The rod was then clamped to the testing machine (Bionix 858, MTS Corp., Eden Prairie, MN, USA) [27]. After the specimen was mounted, pullout force was applied at a constant crosshead rate of $5 \mathrm{~mm} / \mathrm{min}[28,29]$. The force acting on the screw during testing was continuously recorded in $0.05-\mathrm{mm}$ increments until failure. The peak force recorded during the pullout test was defined as the maximum pullout strength for comparison.

\subsection{Quantification of the Embedded Bone Volume (EBV)}

The method used to quantify the bone volume embedded in the screw threads (EBV) was adopted from our previous report [29] and performed by analyzing the radiographic image of the inserted screw using image analysis software (ImageJ, National Institutes of Health, Bethesda, Rockville, MD, USA). The EBV was defined as:

$$
\mathrm{EBV}=\mathrm{A} \times(\pi(\mathrm{D}+\mathrm{d})) / 2
$$

where " $\mathrm{A}$ " denotes the calculated area of bone embedded in the screw threads from a 2-D radiographic image, and " $\mathrm{D}$ " and " $\mathrm{d}$ " denote the outer and inner diameter of the pedicle screw, respectively (Figure 4).

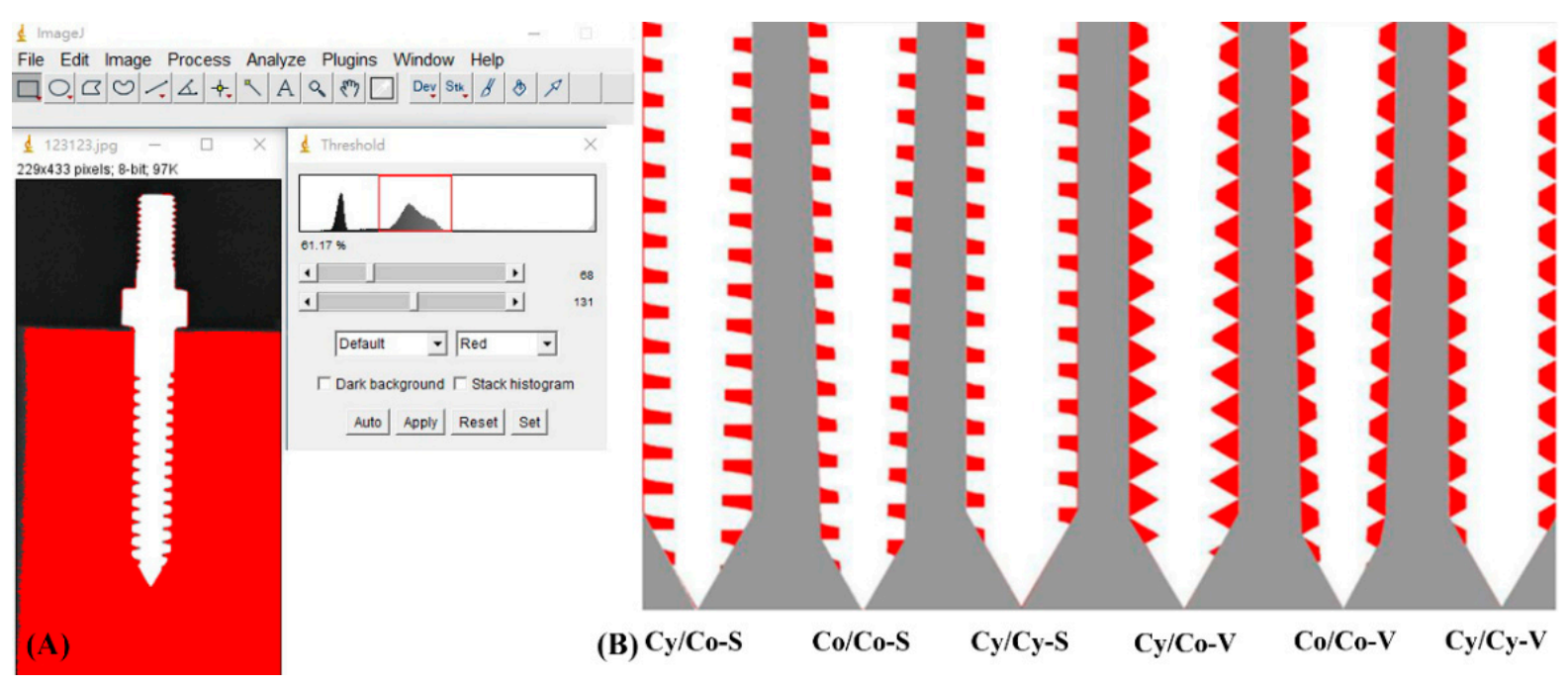

Figure 4. Photographs showing (A) EBV quantification conducted using radiographic imaging of inserted screws and ImageJ analysis software, and (B) the area of bone (highlighted) embedded in the screw threads for various screw geometries. 


\subsection{Statistical Analysis}

To evaluate the effects of bone density and pilot-hole size in six screw-geometric designs, the insertional torque and ultimate pullout force were statistically compared. All of the measurements are expressed as the mean \pm standard deviation (SD). Statistical software (SPSS for Windows version 12.0, SPSS, Inc., Chicago, IL, USA) was used to analyze the pullout strength and insertional torque of all specimens. ANOVA with post hoc analyses was performed to evaluate the differences between groups. Differences were considered to be significant at $p<0.05$.

\section{Results}

\subsection{Effect of Bone Density (Using 3.7-mm Pilot Holes)}

In the 20-pcf group, the insertional torque of $\mathrm{Cy} / \mathrm{Co}-\mathrm{S}, \mathrm{Co} / \mathrm{Co}-\mathrm{S}, \mathrm{Cy} / \mathrm{Cy}-\mathrm{S}, \mathrm{Cy} / \mathrm{Co}-\mathrm{V}$, $\mathrm{Co} / \mathrm{Co}-\mathrm{V}$ and $\mathrm{Cy} / \mathrm{Cy}-\mathrm{V}$ was $2.37 \pm 0.04,2.59 \pm 0.03,2.35 \pm 0.08,2.74 \pm 0.09,2.46 \pm 0.09$ and $1.86 \pm 0.06 \mathrm{~N} \cdot \mathrm{m}$, respectively, compared with $4.54 \pm 0.08,4.71 \pm 0.04,4.56 \pm 0.06$, $4.98 \pm 0.07,4.49 \pm 0.04$ and $3.71 \pm 0.04 \mathrm{~N} \cdot \mathrm{m}$, respectively, in the 30-pcf group (Figure 5). The insertional torque was highest for $\mathrm{Cy} / \mathrm{Co}-\mathrm{V}$ and lowest for $\mathrm{Cy} / \mathrm{Cy}-\mathrm{V}$ among all screw geometries in both the 20-pcf and 30-pcf groups. For the S-threaded screws, Co/Co showed a significantly higher insertional torque than the other two geometries in the 20-pcf group, but there was no significant difference in the 30-pcf group.

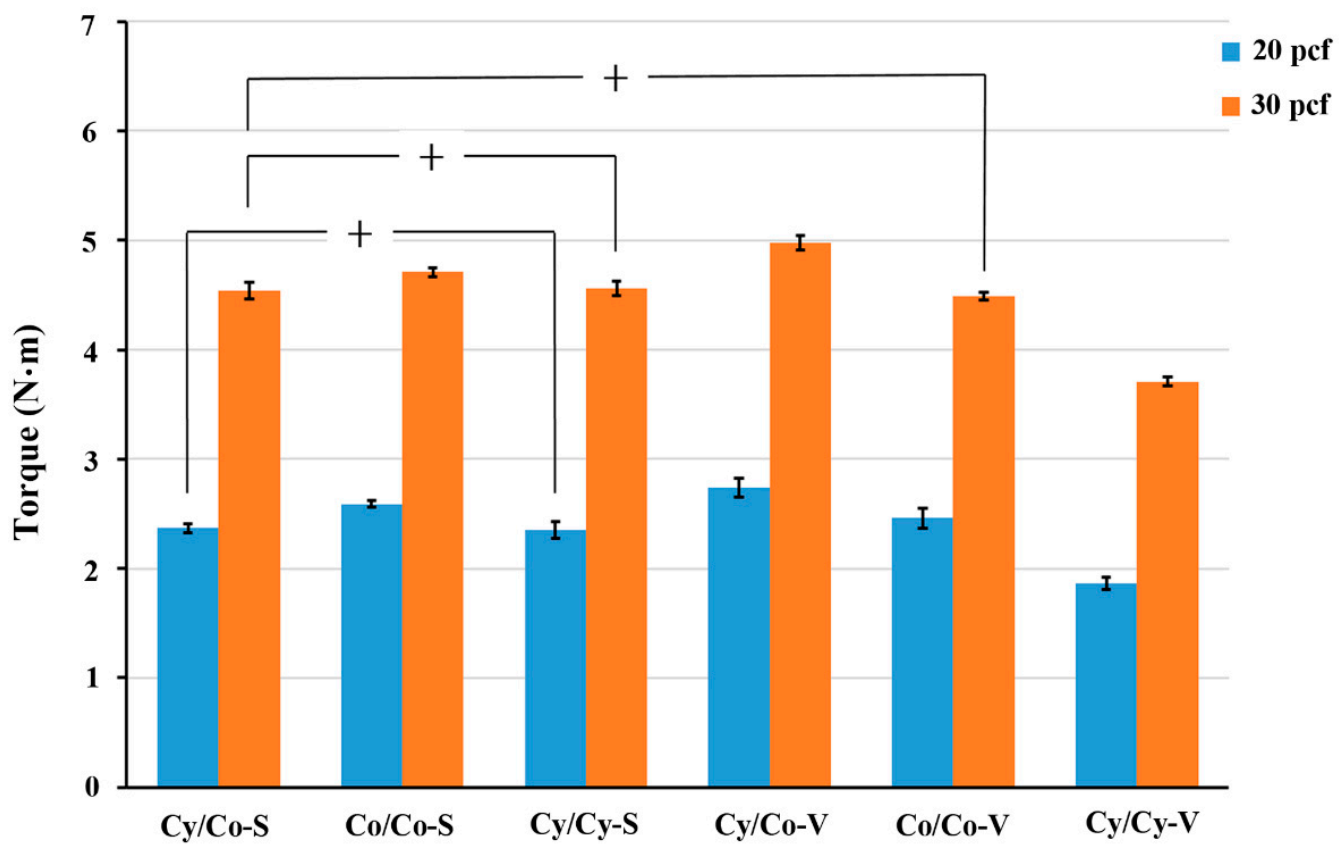

Figure 5. Mean maximal insertion torque for screws of various geometries inserted in a 3.7-mm pilot hole using 20-pcf and 30-pcf test blocks. Groups without significant differences are indicated with the " + " symbol.

In the 20-pcf group, $\mathrm{Cy} / \mathrm{Co}-\mathrm{S}, \mathrm{Co} / \mathrm{Co}-\mathrm{S}, \mathrm{Cy} / \mathrm{Cy}-\mathrm{S}, \mathrm{Cy} / \mathrm{Co}-\mathrm{V}, \mathrm{Co} / \mathrm{Co}-\mathrm{V}$ and $\mathrm{Cy} / \mathrm{Cy}-\mathrm{V}$ showed a maximal pullout strength of $1498.32 \pm 63.88 \mathrm{~N}, 1343.69 \pm 36.92 \mathrm{~N}$, $1497.50 \pm 73.82 \mathrm{~N}, 2109.37 \pm 89.28 \mathrm{~N}, 1951.71 \pm 101.80 \mathrm{~N}$ and $1965.79 \pm 49.18 \mathrm{~N}$, respectively, compared with $3137.38 \pm 86.63 \mathrm{~N}, 2817.87 \pm 114.79 \mathrm{~N}, 3104.66 \pm 140.40 \mathrm{~N}$, $4461.42 \pm 39.61 \mathrm{~N}, 3973.83 \pm 79.88 \mathrm{~N}$ and $4074.93 \pm 71.67 \mathrm{~N}$, respectively, in the 30-pcf group (Figure 6). The pullout strength was significantly higher for the V-threaded screws than for the S-threaded screws in both the 20-pcf and 30-pcf groups. The force was significantly higher for $\mathrm{Cy} / \mathrm{Co}-\mathrm{V}$ than $\mathrm{Cy} / \mathrm{Cy}-\mathrm{V}$ in the 20-pcf group and higher for $\mathrm{Cy} / \mathrm{Co}-\mathrm{V}$ than for the other two geometries in the 30-pcf group. Co/Co-S showed a significantly lower pullout strength than the other screws of the same thread type in the 20- and 30-pcf groups. 


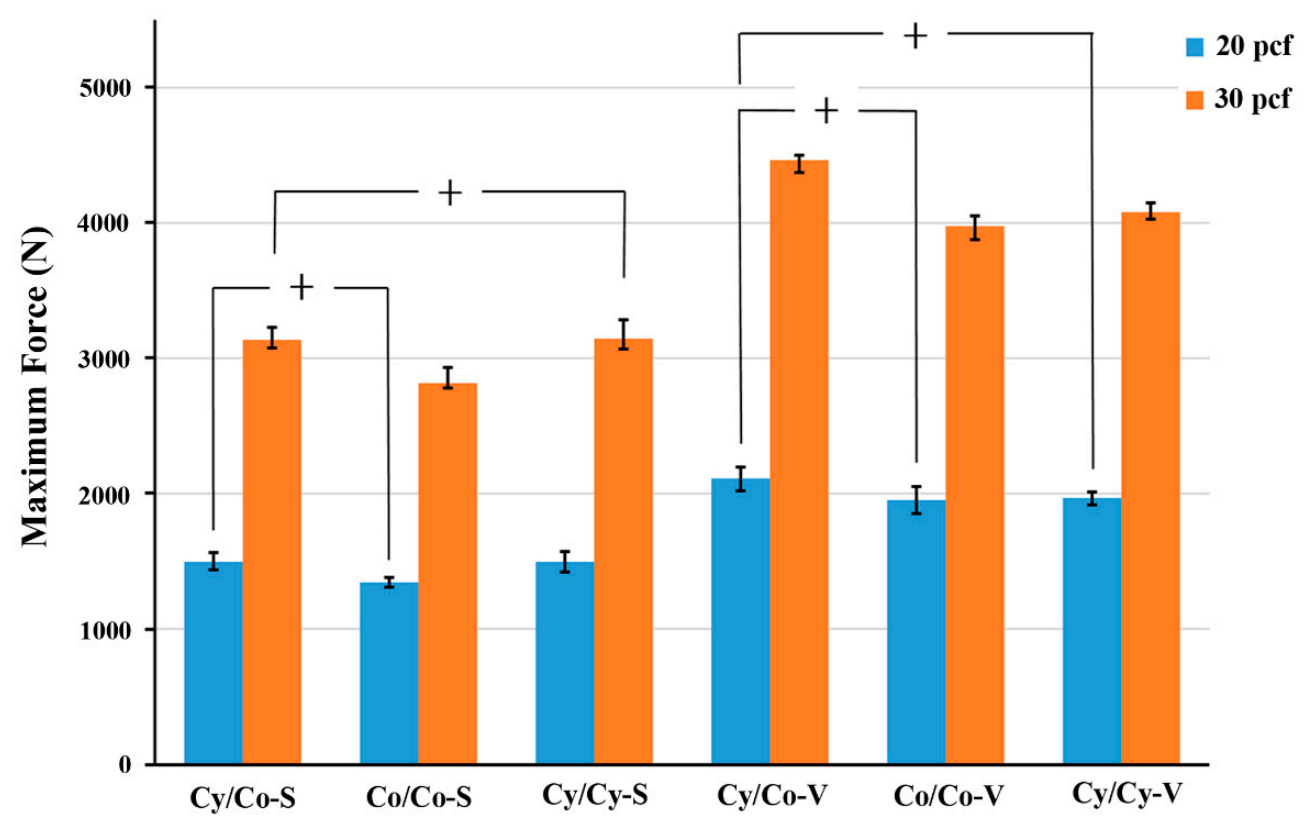

Figure 6. Mean ultimate pullout strength for screws of various geometries inserted in a 3.7-mm pilot hole using 20-pcf and 30-pcf test blocks. Groups without significant differences are indicated with the " + " symbol.

\subsection{Effect of Pilot-Hole Size (Using 20-Pcf Test Blocks)}

In the 2.7-mm pilot-hole group, the insertional torque for $\mathrm{Cy} / \mathrm{Co}-\mathrm{S}, \mathrm{Co} / \mathrm{Co}-\mathrm{S}, \mathrm{Cy} / \mathrm{Cy}-$ $\mathrm{S}, \mathrm{Cy} / \mathrm{Co}-\mathrm{V}, \mathrm{Co} / \mathrm{Co}-\mathrm{V}$ and $\mathrm{Cy} / \mathrm{Cy}-\mathrm{V}$ was $2.85 \pm 0.04,3.02 \pm 0.05,3.02 \pm 0.09,3.33 \pm 0.03$, $2.85 \pm 0.04$ and $2.48 \pm 0.10 \mathrm{~N} \cdot \mathrm{m}$, respectively, compared with $2.65 \pm 0.05,2.77 \pm 0.04$, $2.77 \pm 0.05,3.09 \pm 0.09,2.63 \pm 0.05$ and $2.35 \pm 0.09 \mathrm{~N} \cdot \mathrm{m}$, respectively, in the 3.2-mm group, and $2.37 \pm 0.04,2.59 \pm 0.03,2.35 \pm 0.08,2.74 \pm 0.09,2.46 \pm 0.09$ and $1.86 \pm 0.06 \mathrm{~N} \cdot \mathrm{m}$, respectively, in the 3.7-mm group (Figure 7). The highest and lowest insertional torques were found for $\mathrm{Cy} / \mathrm{Co}-\mathrm{V}$ and $\mathrm{Cy} / \mathrm{Cy}-\mathrm{V}$ in all experimental pilot-hole groups. The insertional torque was significantly higher for $\mathrm{Co} / \mathrm{Co}-\mathrm{S}$ and $\mathrm{Cy} / \mathrm{Cy}-\mathrm{S}$ than for $\mathrm{Cy} / \mathrm{Co}-\mathrm{S}$ in the 2.7and 3.2-mm pilot-hole groups and significantly higher for $\mathrm{Co} / \mathrm{Co}-\mathrm{S}$ than for $\mathrm{Cy} / \mathrm{Co}-\mathrm{S}$ and $\mathrm{Cy} / \mathrm{Cy}-\mathrm{S}$ in the 3.7-mm pilot-hole group. When comparing insertional torque among the three pilot-hole sizes, the value significantly decreased as the pilot-hole size increased.

In the 2.7-mm pilot-hole group, the $\mathrm{Cy} / \mathrm{Co}-\mathrm{S}, \mathrm{Co} / \mathrm{Co}-\mathrm{S}, \mathrm{Cy} / \mathrm{Cy}-\mathrm{S}, \mathrm{Cy} / \mathrm{Co}-\mathrm{V}, \mathrm{Co} / \mathrm{Co}-$ $\mathrm{V}$ and $\mathrm{Cy} / \mathrm{Cy}-\mathrm{V}$ screw geometries showed a maximal pullout strength of $1756.65 \pm 41.36 \mathrm{~N}$, $1627.30 \pm 60.92 \mathrm{~N}, 1745.22 \pm 99.86 \mathrm{~N}, 2285.76 \pm 45.09 \mathrm{~N}, 2259.89 \pm 68.89 \mathrm{~N}$ and $2195.99 \pm 68.72 \mathrm{~N}$, respectively, compared with $1741.22 \pm 77.00 \mathrm{~N}, 1507.24 \pm 97.78 \mathrm{~N}$, $1690.66 \pm 28.93 \mathrm{~N}, 2206.05 \pm 61.34 \mathrm{~N}, 2122.45 \pm 57.62 \mathrm{~N}$ and $2185.54 \pm 59.13 \mathrm{~N}$, respectively, in the 3.2-mm pilot-hole group, and $1498.32 \pm 63.88 \mathrm{~N}, 1343.69 \pm 36.92 \mathrm{~N}$, $1497.50 \pm 73.82 \mathrm{~N}, 2109.37 \pm 89.28 \mathrm{~N}, 1951.71 \pm 101.80 \mathrm{~N}$ and $1965.79 \pm 49.18 \mathrm{~N}$, respectively, in the 3.7-mm pilot-hole group (Figure 8). The maximal pullout strength was significantly higher for the V-threaded screws than for the S-threaded screws for all three pilot-hole sizes. In the S-threaded group, the pullout strength was significantly lower for $\mathrm{Co} / \mathrm{Co}$ than for the other two geometries for all three pilot-hole sizes. In the V-threaded group, the pullout strength was significantly higher for $\mathrm{Cy} / \mathrm{Co}$ than $\mathrm{Cy} / \mathrm{Cy}$ in the 2.7- and $3.7-\mathrm{mm}$ pilot-hole groups and significantly higher for $\mathrm{Cy} / \mathrm{Co}$ than $\mathrm{Co} / \mathrm{Co}$ in the $3.2-\mathrm{mm}$ pilot-hole group. 


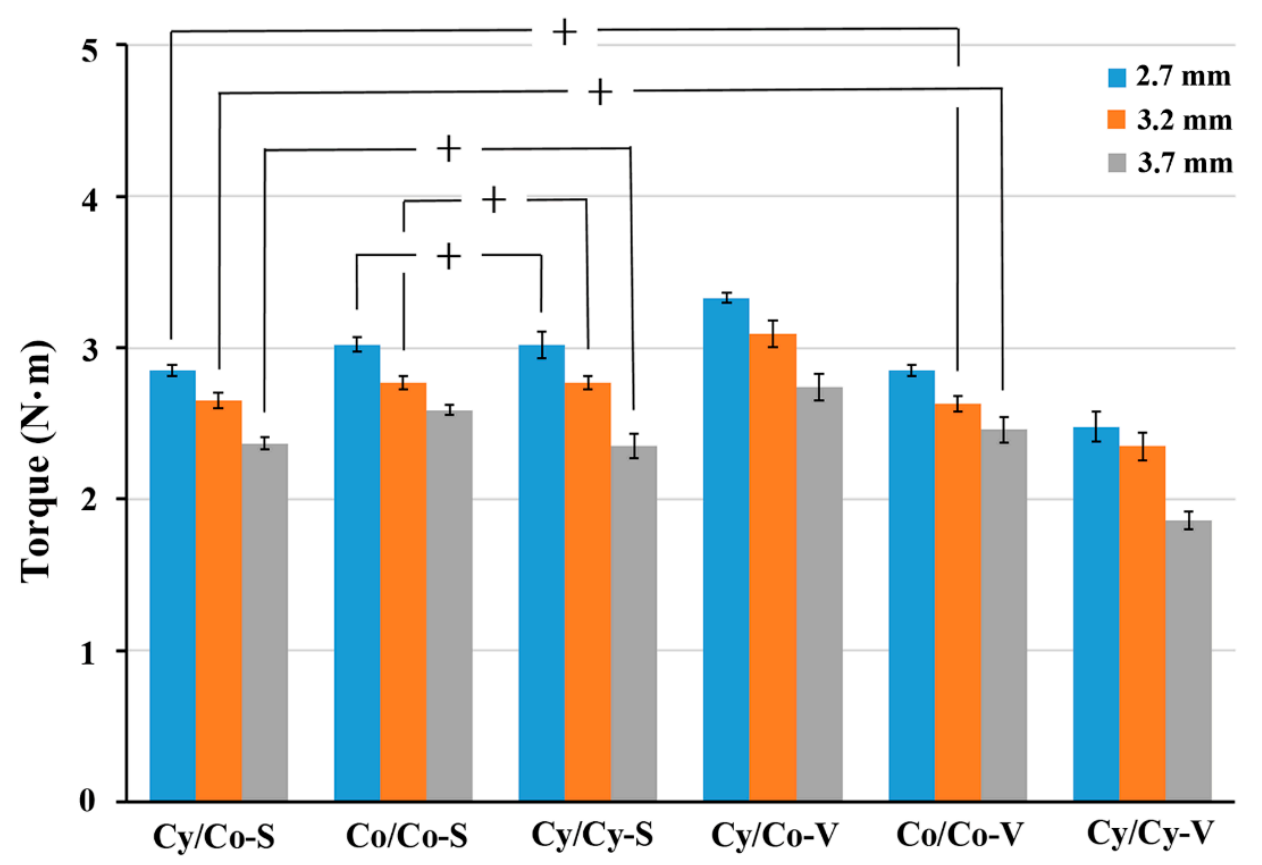

Figure 7. Mean maximal insertional torque for screws of various geometries inserted in 2.7-mm, 3.2-mm and 3.7-mm pilot holes using 20-pcf test blocks. Groups without significant differences are indicated with the "+" symbol.

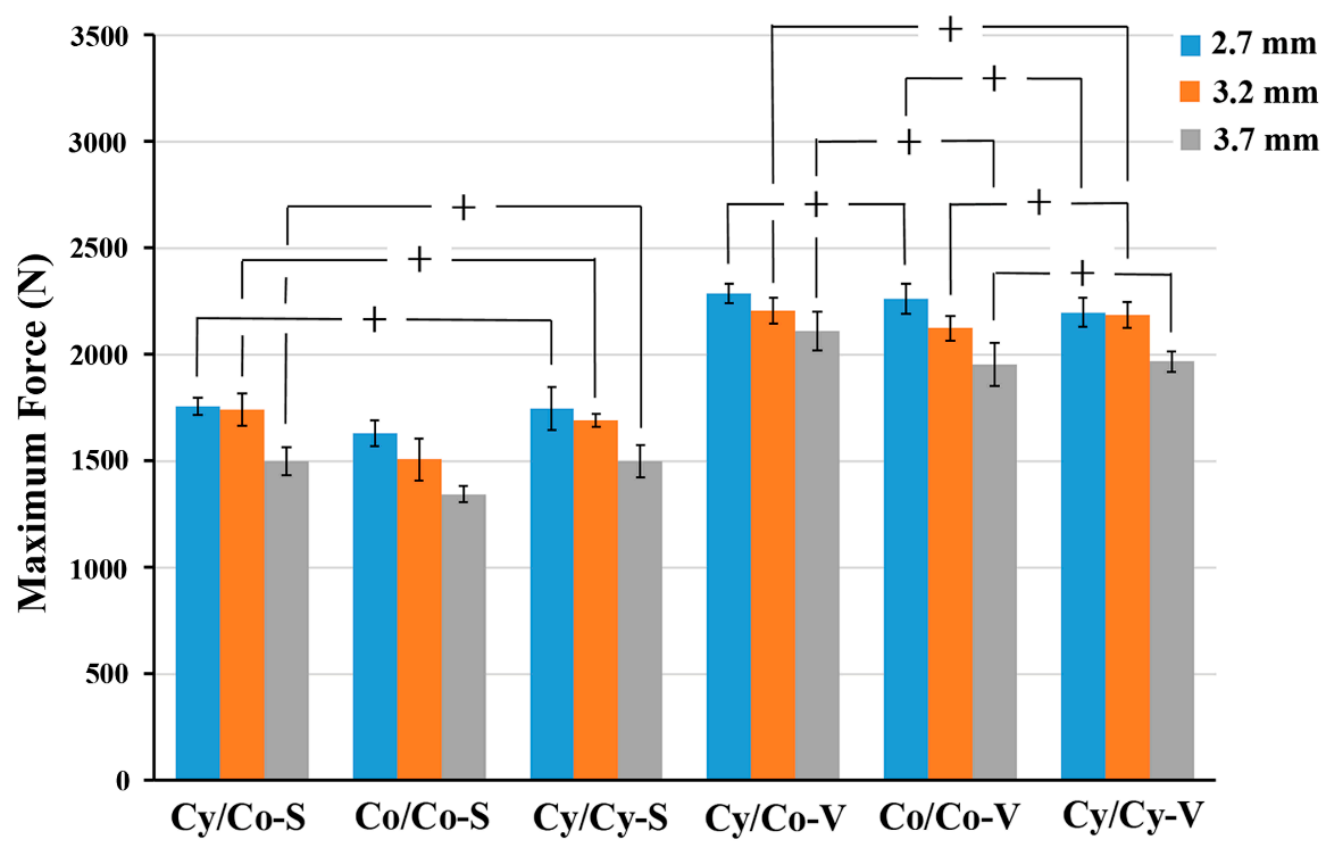

Figure 8. Mean ultimate pullout strength for screws of various geometries inserted in 2.7-mm, 3.2-mm and 3.7-mm pilot holes using 20-pcf test blocks. Groups without significant differences are indicated with the "+" symbol.

\subsection{Embedded Bone Volume (EBV)}

The volumes of bone embedded in the Cy/Co-S, Co/Co-S, Cy/Cy-S, Cy/Co-V, Co/Co$\mathrm{V}$ and $\mathrm{Cy} / \mathrm{Cy}-\mathrm{V}$ screw threads were $302.47,226.48,268.11,372.41,320.04$ and $359.16 \mathrm{~mm}^{3}$, respectively (Figure 9A). The EBV was higher for the V-threaded screws than for the Sthreaded screws. In the S-threaded group, the EBV was lower for Co/Co than for the other two geometries, whereas in the V-threaded group, the EBV was significantly higher 
for $\mathrm{Cy} / \mathrm{Co}$ than for the other two geometries. A strong positive correlation $\left(\mathrm{R}^{2}=0.8595\right)$ between the pullout strength and the EBV was noted for all screws (Figure 9B).

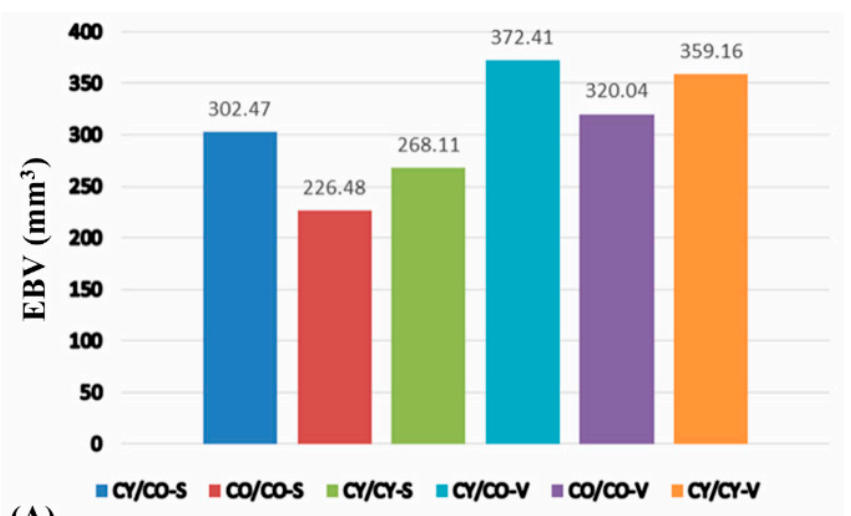

(A)

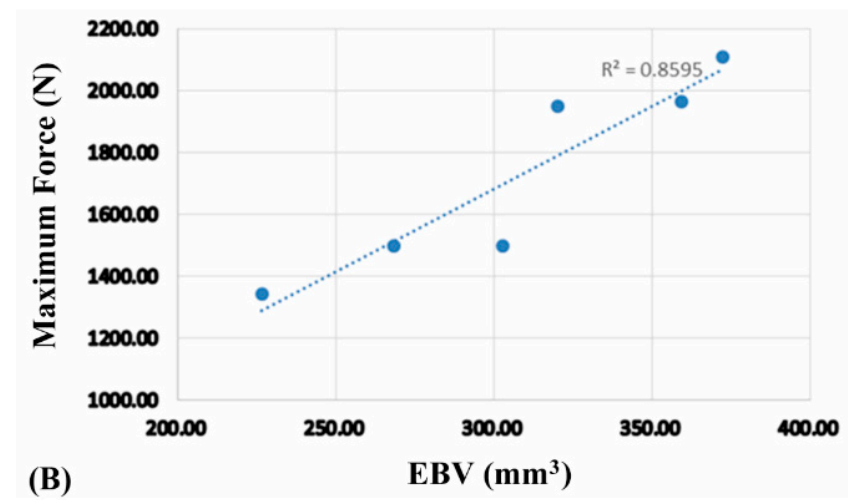

Figure 9. (A) The EBV and (B) the relationship between the pullout strength and EBV for various screw geometries. A strong positive correlation $\left(R^{2}=0.8595\right)$ was noted after comparing the pullout strength of all screws with the EBV.

\section{Discussion}

The distribution of insertional torque and pullout strength differed by density, with the $\mathrm{Cy} / \mathrm{Co}-\mathrm{V}$ screw geometry exhibiting the highest value for both. The pullout strength was significantly higher for the V-threaded screws than for the S-threaded screws in the 20- and 30-pcf groups, but this phenomenon was not observed for insertional torque. The relationship between insertional torque and pullout strength is still under debate. The pullout strength, which refers to the strength required to extract a screw through its longitudinal axis, has been described as a critical parameter for judging the fixation stability of pedicle screws. However, there is no method for testing the pullout strength during surgery without affecting fixation. Another easy but subjective parameter is insertion torque, which is a subjective value determined by the surgeon during screw insertion. Controversies between pullout strength and insertional toque do exist. In the study, both the pullout strength and the insertional toque could be mutually compared using this standardized polyurethane foam. Ricci et al. performed biomechanical testing using screws with threads of varying pitch in osteoporotic test blocks and found a higher maximal insertional torque with increasing pitch but no change in pullout strength [16]. The results obtained using the osteoporotic test blocks in their study may not be comparable to those obtained using the normal and higher-than-normal bone density blocks in our study. Addevico et al. tested screws of three different pitches in blocks of three different densities to clarify the correlation between bone density and screw pitch [17]. In their study, torque was related to pullout strength in all configurations, and medium-sized screws showed the highest biomechanical strength. However, the cannulated, partially threaded screws used 
in their study were not comparable to the non-cannulated, fully threaded screws used in our study. Shah et al. found that both the maximum insertional torque and pullout strength were significantly and positively correlated when tested using blocks with a bone density that was higher than normal [19]. However, the geometric design of the orthodontic mini-screws used in their study was completely different from that of the pedicle screws used in our study. Kim et al. evaluated the pullout strength of nine pedicle screw geometries in standardized polyurethane foams of grades 5, 15 and 20 and concluded that the value was higher in the V-threaded group and highest for the Cy/Co-V type [21]. The conflicting pullout strength results obtained using osteoporotic test blocks [16,21] and the screw fatigue induced by the decreased inner diameter of the neck design in their study [30] limited further clinical applications. The varying results for insertional torque may also have been caused by differences in measurement methods. The insertional torque reflected the manual sensation experienced when inserting screws, and the last portion of the threading process was supposed to be much more important than the whole insertion process. The insertional torque was measured during the last portion of the threading process in our study; however, in other studies, maximal values were recorded by digital meters throughout the screw insertion process [16,19], which is less clinically practical. In our study, both the pullout strength and the insertional toque were mutually compared, and the highest value from both methods was found for the Cy/Co-V screw geometry.

A significant difference was observed in the pullout strength between the different bone densities. The pullout strength was significantly higher for $\mathrm{Cy} / \mathrm{Co}-\mathrm{V}$ than for $\mathrm{Co} / \mathrm{Co}-$ $\mathrm{V}$ and $\mathrm{Cy} / \mathrm{Cy}-\mathrm{V}$ in the 30-pcf group but it was only higher than that of $\mathrm{Cy} / \mathrm{Cy}-\mathrm{V}$ in the 20-pcf group. The effect of screw geometry on pullout strength increased as bone density increased [17]. Previous studies reported an effect of the outer/inner diameter shape or thread type on the pullout strength, leading to the conclusion that a conical core compressed the surrounding bone during screw insertion, thereby increasing the insertional torque and pullout strength [31,32]; this was further confirmed with finite element analyses [33,34]. Krenn et al. used the concept of the flank overlap area, the contact surface between the implant and engaged bone, to illustrate that decreasing the inner diameter and maintaining the outer diameter of the screw would increase the compression of adjacent bone and, thus, increase the pullout strength [35]. The novelty of our study is that we quantified the EBV for various screw geometries and further compared the EBV with the pullout strength. A strong positive correlation $\left(\mathrm{R}^{2}=0.8595\right)$ was found between the EBV and the pullout strength, and $\mathrm{Cy} / \mathrm{Co}-\mathrm{V}$ showed the highest EBV and pullout strength values among all the screw geometries. Our results demonstrated that the pullout strength could be evaluated by EBV for bone with a homogenous density.

Our biomechanical data show that smaller pilot holes lead to higher insertional torques and pullout strengths. Although these results are similar to those of previous studies $[15,20,22]$, our study is novel in the control of the screw size, bone density and pilot-hole tapping method. Ferris et al. inserted 10 different commercialized pedicle screws into 20-pcf test blocks using tapped $(3.17 \mathrm{~mm})$ or untapped pilot holes and found that the pullout strength was lower for tapped than for untapped holes [15]. However, consistent results are difficult to obtain due to highly variable screw geometries and sizes. Battula et al. used self-tapping cortical bone screws inserted into synthetic osteoporotic bone with pilot holes of different sizes, ranging from 70 to $80 \%$ of the outer diameter, and found that a pilothole size of $71.5 \%$ of the outer diameter was a critical threshold for pullout strength [20]. These results are not comparable to those of our study because of the osteoporotic density and unclear thread types. Defino et al. evaluated the insertional torque and pullout force of two sizes of pedicle screws with different pilot-hole sizes and found that the fixation stability was influenced even when using pilot holes that were smaller than the screw sizes [22]. A rough conclusion may be drawn by using pilot-holes that are only one size smaller than the outer screw diameter.

The largest pilot hole used in the present study was $3.7 \mathrm{~mm}$, which was smaller than the inner diameter of the tested screws and allowed the use of the EBV to evaluate the 
pullout strength. For all three pilot-hole sizes, the pullout strength was higher for the Vthreaded screws than for the S-threaded screws, and $\mathrm{Cy} / \mathrm{Co}-\mathrm{V}$ showed the highest pullout strength among the other screw geometries, which corresponds to the graph showing the correlation between the pullout force and the EBV.

There was no significant difference in the insertional torque between the V-threaded and S-threaded groups for either density or for any of the three pilot-hole sizes, which means that the manual sensation experienced during clinical screw insertion and the value of insertional torque cannot represent the true screw fixation stability. For example, the lowest torque exhibited by $\mathrm{Cy} / \mathrm{Cy}-\mathrm{V}$ did not correspond to the lowest pullout strength among all six configurations. Spinal fusion surgeries are performed for a wide spectrum of indications, including trauma, infection, tumor, deformity and congenital anomalies. The goal of spinal fusion is to realign normal anatomy and restore biomechanical stability. Inadequate fixation and subsequent motion may cause pseudarthrosis-induced axial back pain, subsequent implant failure or interbody cage retropulsion [36,37]. The superior biomechanical performance of $\mathrm{Cy} / \mathrm{Co}-\mathrm{V}$ screws could be clinically recommended to ensure secure fixation.

The present study has some limitations. First, the homogenous bone density of the test blocks cannot represent that of bone or vertebrae in the clinic; thus, the use of EBV to estimate pullout strength could not be applied to real vertebrae. More variables, such as the screw trajectory angle/tract, the density distribution and the anatomy of each specimen, should be considered if using cadaveric vertebrae. Second, our data only represent biomechanical testing in samples of a normal and higher-than-normal bone density; the clinically common osteoporotic bone density was not examined. A larger pilot-hole size of over $71.5 \%$ of the outer diameter [20] could be applied to create a control group with a nonsignificant pullout strength.

\section{Conclusions}

Our study shows that screws with V-shaped threads exhibited a higher pullout strength than screws with S-shaped threads for different densities and pilot-hole sizes. Screws with an outer cylindrical shape, an inner conical shape and V-shaped threads showed the highest insertional torque and pullout strength at a normal and higher-thannormal bone density and could be recommended for further use in clinical practice. Even with the increasing of the pilot-hole size, this configuration remained superior. Due to the strong positive correlation, the pullout strength could be evaluated by the EBV in standardized homogenous polyurethane foam.

Author Contributions: Conceptualization, M.-K.H. and C.-L.T.; methodology, Y.-D.L., M.-Y.L. and C.-X.L.; software, M.-Y.L. and C.-X.L.; validation, M.-K.H., Y.-D.L., T.-T.T. and P.-L.L.; formal analysis, Y.-D.L., T.-T.T. and C.-L.T.; investigation, M.-K.H., Y.-D.L., P.-L.L. and C.-L.T.; data curation: Y.-D.L., T.-T.T. and P.-L.L.; supervision: C.-L.T.; writing—original draft preparation, M.-K.H.; writing-review and editing, Y.-D.L. and C.-L.T.; funding acquisition, C.-L.T. All authors have read and agreed to the published version of the manuscript.

Funding: This work was supported by the Chang Gung Memorial Hospital (CMRPD2K0091, CMRPD2K0092).

Institutional Review Board Statement: Not applicable.

Informed Consent Statement: Not applicable.

Data Availability Statement: The data used to support the finding of this study are available from the corresponding author upon request.

Conflicts of Interest: The authors declare no conflict of interest. 


\section{References}

1. Ohrt-Nissen, S.; Dahl, B.; Gehrchen, M. Choice of rods in surgical treatment of adolescent idiopathic scoliosis: What are the clinical implications of biomechanical properties?-A review of the literature. Neurospine 2018, 15, 123-130. [CrossRef]

2. Tsirikos, A.I. Correction of Adolescent Idiopathic Scoliosis Using a Convex Pedicle Screw Technique: A Novel Technique for Deformity Correction. JBJS Essent. Surg. Tech. 2019, 9, 1-13. [CrossRef] [PubMed]

3. Suk, S.I.L.; Kim, J.H.; Kim, S.S.; Lim, D.J. Pedicle screw instrumentation in adolescent idiopathic scoliosis (AIS). Eur. Spine J. 2012, 21, 13-22. [CrossRef]

4. Nouh, M.R. Spinal fusion-hardware construct: Basic concepts and imaging review. World J. Radiol. 2012, 4, 193-207. [CrossRef] [PubMed]

5. Frost, B.A.; Camarero-Espinosa, S.; Johan-Foster, E. Materials for the spine: Anatomy, problems, and solutions. Materials 2019, 12, 253. [CrossRef]

6. Obid, P.; Danyali, R.; Kueny, R.; Huber, G.; Reichl, M.; Richter, A.; Niemeyer, T.; Morlock, M.; Püschel, K.; Übeyli, H. Hybrid Instrumentation in Lumbar Spinal Fusion: A Biomechanical Evaluation of Three Different Instrumentation Techniques. Glob. Spine J. 2017, 7, 47-53. [CrossRef]

7. Reichl, M.; Kueny, R.A.; Danyali, R.; Obid, P. Biomechanical Effects of a Dynamic Topping off Instrumentation in a Long Rigid Pedicle Screw Construct. Clin. Spine Surg. 2017, 30, E440-E447. [CrossRef] [PubMed]

8. Lamerain, M.; Bachy, M.; Delpont, M.; Kabbaj, R.; Mary, P.; Vialle, R. CoCr rods provide better frontal correction of adolescent idiopathic scoliosis treated by all-pedicle screw fixation. Eur. Spine J. 2014, 23, 1190-1196. [CrossRef]

9. Murphy, M.E.; Gilder, H.; Maloney, P.R.; McCutcheon, B.A.; Rinaldo, L.; Shepherd, D.; Kerezoudis, P.; Ubl, D.S.; Crowson, C.S.; Krauss, W.E.; et al. Lumbar decompression in the elderly: Increased age as a risk factor for complications and nonhome discharge. J. Neurosurg. Spine. 2017, 26, 353-362. [CrossRef]

10. Turcotte, J.J.; Patton, C.M. Predictors of Postoperative Complications After Surgery for Lumbar Spinal Stenosis and Degenerative Lumbar Spondylolisthesis. J. Am. Acad. Orthop. Surg. Glob. Res. Rev. 2018, 2, e085. [CrossRef]

11. Reid, J.J.; Johnson, J.S.; Wang, J.C. Challenges to bone formation in spinal fusion. J. Biomech. 2011, 44, 213-220. [CrossRef]

12. Gruskay, J.A.; Webb, M.L.; Grauer, J.N. Methods of evaluating lumbar and cervical fusion. Spine J. 2014, 14, 531-539. [CrossRef]

13. Chun, D.S.; Baker, K.C.; Hsu, W.K. Lumbar pseudarthrosis: A review of current diagnosis and treatment. Neurosurg. Focus 2015, 39, E10. [CrossRef] [PubMed]

14. Meng, B.; Bunch, J.; Burton, D.; Wang, J. Lumbar interbody fusion: Recent advances in surgical techniques and bone healing strategies. Eur. Spine J. 2021, 30, 22-33. [CrossRef] [PubMed]

15. Pfeiffer, F.M.; Abernathie, D.L. A comparison of pullout strength for pedicle screws of different designs: A study using tapped and untapped pilot holes. Spine 2006, 31, E867-E870. [CrossRef] [PubMed]

16. Ricci, W.M.; Tornetta, P.; Petteys, T.; Gerlach, D. A comparison of screw insertion torque and pullout strength. J. Orthop. Trauma 2010, 24, 374-378. [CrossRef]

17. Addevico, F.; Morandi, M.; Scaglione, M.; Solitro, G.F. Screw insertion torque as parameter to judge the fixation. Assessment of torque and pull-out strength in different bone densities and screw-pitches. Clin. Biomech. 2020, 72, 130-135. [CrossRef] [PubMed]

18. Amirouche, F.; Solitro, G.F.; Magnan, B.P. Stability and Spine Pedicle Screws Fixation Strength-A Comparative Study of Bone Density and Insertion Angle. Spine Deform. 2016, 4, 261-267. [CrossRef]

19. Shah, A.H.; Behrents, R.G.; Kim, K.B.; Kyung, H.-M.; Buschang, P.H. Effects of screw and host factors on insertion torque and pullout strength. Angle Orthod. 2012, 82, 603-610. [CrossRef]

20. Battula, S.; Schoenfeld, A.J.; Sahai, V.; Vrabec, G.A.; Tank, J.; Njus, G.O. The effect of pilot hole size on the insertion torque and pullout strength of self-tapping cortical bone screws in osteoporotic bone. J. Trauma 2008, 64, 990-995. [CrossRef]

21. Kim, Y.Y.; Choi, W.S.; Rhyu, K.W. Assessment of pedicle screw pullout strength based on various screw designs and bone densities-An ex vivo biomechanical study. Spine J. 2012, 12, 164-168. [CrossRef]

22. Defino, H.L.A.; Miranda, R.F.; Pinheiro, R.P.; Shimano, A. Influence of diameter and geometry in the tapping of the pilot hole in pedicle screws. Coluna/Columna 2019, 18, 51-54. [CrossRef]

23. Zdero, R.; Olsen, M.; Bougherara, H.; Schemitsch, E.H. Cancellous bone screw purchase: A comparison of synthetic femurs, human femurs, and finite element analysis. Proc. Inst. Mech. Eng. Part H J. Eng. Mech. 2008, 222, 1175-1183. [CrossRef] [PubMed]

24. Shea, T.M.; Laun, J.; Gonzalez-Blohm, S.A.; Doulgeris, J.J.; Lee, W.E.; Aghayev, K.; Vrionis, F.D. Designs and Techniques That Improve the Pullout Strength of Pedicle Screws in Osteoporotic Vertebrae: Current Status. BioMed Res. Int. 2014, 2014. [CrossRef] [PubMed]

25. Varghese, V.; Saravana Kumar, G.; Krishnan, V. Effect of various factors on pull out strength of pedicle screw in normal and osteoporotic cancellous bone models. Med. Eng. Phys. 2017, 40, 28-38. [CrossRef]

26. ASTM F1839-08 (2016) Standard Specification for Rigid Polyurethane Foam for Use as a Standard Material for Testing Orthopaedic Devices and Instruments. Available online: https:/ /www.astm.org/Standards/F1839.htm (accessed on 2 April 2020).

27. Chen, L.H.; Tai, C.L.; Lee, D.M.; Lai, P.L.; Lee, Y.C.; Niu, C.C.; Chen, W.J. Pullout strength of pedicle screws with cement augmentation in severe osteoporosis: A comparative study between cannulated screws with cement injection and solid screws with cement pre-filling. BMC Musculoskelet. Disord. 2011, 12, 33. [CrossRef]

28. Liu, M.Y.; Tsai, T.T.; Lai, P.L.; Hsieh, M.K.; Chen, L.H.; Tai, C.L. Biomechanical comparison of pedicle screw fixation strength in synthetic bones: Effects of screw shape, core/thread profile and cement augmentation. PLoS ONE 2020, 15, e0229328. [CrossRef] 
29. Hsieh, M.K.; Liu, M.Y.; Chen, J.K.; Tsai, T.T.; Lai, P.L.; Niu, C.C.; Tai, C.L. Biomechanical study of the fixation stability of broken pedicle screws and subsequent strategies. PLOS ONE 2019, 14, e0219189. [CrossRef]

30. Cho, W.; Cho, S.K.; Wu, C. The biomechanics of pedicle screw-based instrumentation. J. Bone Jt. Surg-Ser. B. 2010, 92, 1061-1065. [CrossRef] [PubMed]

31. Ono, A.; Brown, M.D.; Latta, L.L.; Milne, E.L.; Holmes, D.C. Triangulated pedicle screw construct technique and pull-out strength of conical and cylindrical screws. J. Spinal Disord. 2001, 14, 323-329. [CrossRef]

32. Abshire, B.B.; McLain, R.F.; Valdevit, A.; Kambic, H.E. Characteristics of pullout failure in conical and cylindrical pedicle screws after full insertion and back-out. Spine J. 2001, 1, 408-414. [CrossRef]

33. Chao, C.K.; Hsu, C.C.; Wang, J.L.; Lin, J. Increasing Bending Strength and Pullout Strength in Conical Pedicle Screws: Biomechanical Tests and Finite Element Analyses. J. Spinal Disord. Tech. 2008, 21, 130-138. [CrossRef]

34. Hsu, C.C.; Chao, C.K.; Wang, J.L.; Hou, S.M.; Tsai, Y.T.; Lin, J. Increase of pullout strength of spinal pedicle screws with conical core: Biomechanical tests and finite element analyses. J. Orthop. Res. 2005, 23, 788-794. [CrossRef] [PubMed]

35. Krenn, M.H.; Piotrowski, W.P.; Penzkofer, R.; Augat, P. Influence of thread design on pedicle screw fixation. Laboratory investigation. J. Neurosurg. Spine 2008, 9, 90-95. [CrossRef]

36. Kimura, H.; Shikata, J.; Odate, S.; Soeda, T.; Yamamura, S. Risk factors for cage retropulsion after posterior lumbar interbody fusion: Analysis of 1070 cases. Spine 2012, 37, 1164-1169. [CrossRef] [PubMed]

37. Lee, D.Y.; Park, Y.J.; Song, S.Y.; Jeong, S.T.; Kim, D.H. Risk Factors for Posterior Cage Migration after Lumbar Interbody Fusion Surgery. Asian Spine J. 2018, 12, 59-68. [CrossRef] 